\title{
Identification of Diagenetic Facies Based on Diagenetic Process: An Example from Paleogene Lake Sediment Sandstone in Bozhong $X$ Oilfield
}

\author{
Qian Wendao ${ }^{1}$, Yin Taiju ${ }^{1, ~}$, Sun Shaochuan ${ }^{2}$, Zhang Changmin $^{1}$, Hou Guowei ${ }^{3}$, He Miao $^{3}$, \\ Xia Min ${ }^{1}$ \\ ${ }^{1}$ School of Geoscience of Yangtze University, Wuhan, China \\ ${ }^{2}$ Zhongyuan Oilfield of Sinopec, Puyang, China \\ ${ }^{3}$ Shanghai Branch of CNOOC Ltd., Shanghai, China \\ Email address: \\ 932408129@qq.com (Qian Wendao),yintaij@yangtzeu.edu.cn (Yin Taiju), 515587929@qq.com (Sun Shaochuan), \\ zcm@yangtzeu.edu.cn (Zhang Changmin), hougw@cnooc.com.cn (Hou Guowei), 905665922@qq.com (He Miao), \\ 736519400@qq.com (Xia Min) \\ ${ }^{*}$ Corresponding author
}

\section{To cite this article:}

Qian Wendao, Yin Taiju, Sun Shaochuan, Zhang Changmin, Hou Guowei, He Miao, Xia Min. Identification of Diagenetic Facies Based on Diagenetic Process: An Example from Paleogene Lake Sediment Sandstone in Bozhong X Oilfield. Earth Sciences.

Vol. 7, No. 4, 2018, pp. 158-165. doi: 10.11648/j.earth.20180704.13

Received: June 3, 2018; Accepted: June 19, 2018; Published: July 7, 2018

\begin{abstract}
Based on diagenetic evolution, reservoir diagenetic facies evolution was restored in burial history through quantitatively calculating the original porosity reconstructed by compaction, cementation and dissolution using core measurement data. The essence of this method was illustrated and its effectiveness was demonstrated using Paleogene lake sediment sandstone in Bozhong X oilfield, Bohai Bay Basin, China. Because diagenetic field changes as the structure depth increases or decreases and acts on deposition, diagenetic facies can be significantly different in different geological period. The $\mathrm{Ed}_{1}$ reservoir has experienced such an evolutionary process of W-Com_W-Cla-C_M-Car-C to M-Com_M-Clay-C_W-Qua-C_W-Fel-D_W-Car-D to M-Com_M-Cla-C_W-Qua-C_W-Fel-D_W-Car-D, while the Ed ${ }_{2}$, the Ed $\mathrm{Ed}_{3}$ and the $\mathrm{Es}_{1}{ }_{1}$ are W-Com_W-Cla-C to M-Com_M-Cla-C-S-Com_S-Clay-C_W-Qua-C_W-Fel-D to S-Com_S-Cla-C_W-Qua-C_M-Fel-D, M-Com_W-Cla-C_W-Qua-C_W-Fel-D to M-Com_M-Cla-C_W-Qua-C_W-Fel-D to S-Com_M-Clay-C_W-Qua-C_S-Fel-D to S-Com_S-Clay-C_M-Qua-C_S-Fel-D and M-Com_W-Cla-C_W-Car-C to M-Com_M-Cla-C_W-Car-C_M-Fel-D_W-Car-D to M-Com_M-Clay-C_S-Fel-D_M-Car-D to S-Com_M-Cla-C _S-Fel-D_ M-Car- $-\bar{D}$ respectively. Through this study, the reason for the dynamic change of sand body in the diagenetic field and the anisotropy of the reservoir are revealed.
\end{abstract}

Keywords: Diagenetic Stages, Clastic Sandstones, Bozhong Oilfield, Diagenetic Simulation, Diagenetic Facies

\section{Introduction}

It is now evident that porosity and permeability of clastic rock are closely related with diagenesis, and thus research on diagenesis has important significance for petroleum exploration and development (Rashid D.D., 1985; Craig E.M., 1994; Theodore T.M., 1996; Dacid B.B., 2001). In the diagenesis process, diagenetic field changes as the structure depth increases or decreases and acts on deposition, diagenetic facies can be significantly different in different geological period.

Diagenetic facies is a product of both diagenesis and diagenetic stages under the effect of tectonics, and the type of diagenetic facies is closely connected with rock particles, dissolution, cementation, fabric, pores and cracking. A naming scheme for diagenetic facies, such as low porosity and low porosity-coarse grained feldspar lithic sandstone-feldspar dissolution facies, has been proposed, a method taking lithology, diagenesis and pore permeability 
into consideration when dividing diagenetic facies (Zhou Caineng, 2008; K.E. Higgs et al., 2016). This method can detailedly describe reservoir characteristics, while it is not convenient for practical application. In essence, diagenetic facies is the sum of petrology, geochemistry and rock physics that reflect the diagenetic environment. The naming of diagenetic facies emphasizes diagenesis and diagenesis in the diagenetic environment is proposed (Chen Yanhua, 1994; Zhong Guang method, 1997; Du Yebo et cl., 2006). Method taking lithology and main diagenesis into consideration describes diagenetic facies like this "sandstone- cementation facies", while single factor diagenetic facies emphasis the main diagenesis, for example, quartz secondary increase diagenetic facies. Because of the complexity of diagenesis, single factor diagenetic facies is difficult to avoid the one-sided description of reservoir diagenetic characteristics. Some methods emphasize the diagenesis and diagenetic process, naming the diagenetic facies with important diagenesis that determines the physical characteristics of the reservoir, such as medium strong dissolving-middle glue formation facies (Grigsby J D et al., 1996; Elfigih et al., 1999; Xia Qinglong et al., 2012). Sedimentary-diagenetic facies takes sedimentary facies and diagenesis into consideration and the sedimentary-diagenetic facies can be identified effectively from logging data through the use of the discriminant analysis and corresponding crossplots (Jian Wang et al., 2017). Based on basis of previous studies, a new method is proposed through synthetical consideration of all diagenesis and its strength in different diagenetic stage.

\section{Materials and Methods}

\subsection{Geological Setting and Samples}

The Bozhong X oilfield is located in the southwest of Bohai and surrounded by the Bozhong sag, the Shanan sag, the Bonan uplift and the Sha Leitian uplift. It is one of the most favorable areas for oil and gas enrichment in Bohai. The basin is filled with Cenozoic sediments including the Kongdian (Ek), Shahejie (Es), Dongying(Ed), Guantao (Ng), Minghuazhen $(\mathrm{Nm})$ and Pingyuan (Qp) formations. The Dongying formation (Ed) can be divided into three members from the base to the top, which are $\mathrm{Ed} 3, \mathrm{Ed} 2$ and $\mathrm{Ed} 1$ respectively (Figure 1). The tectonic evolution of the basin consists of a synrift stage (65.0 to $24.6 \mathrm{Ma})$ and a postrift stage (24.6 Ma to the present), and Ed2 reservoir sedimentation period is from about $29.7 \mathrm{Ma}$ to $28.1 \mathrm{Ma}(\mathrm{Xu}$ Jie et al., 2015). X well is sampled for the investigation of diagenetic facies evolution in the lake sandstones (Figure 1, Figure 2). The content of the rocks, petro physical property, diagenesis including clay cementation, carbonate cementaion, quartz cementation and feldspar dissolution and carbonate dissolution in Dongying Formation and Shahejie Formaiton of well $\mathrm{X}$ are analyzed.

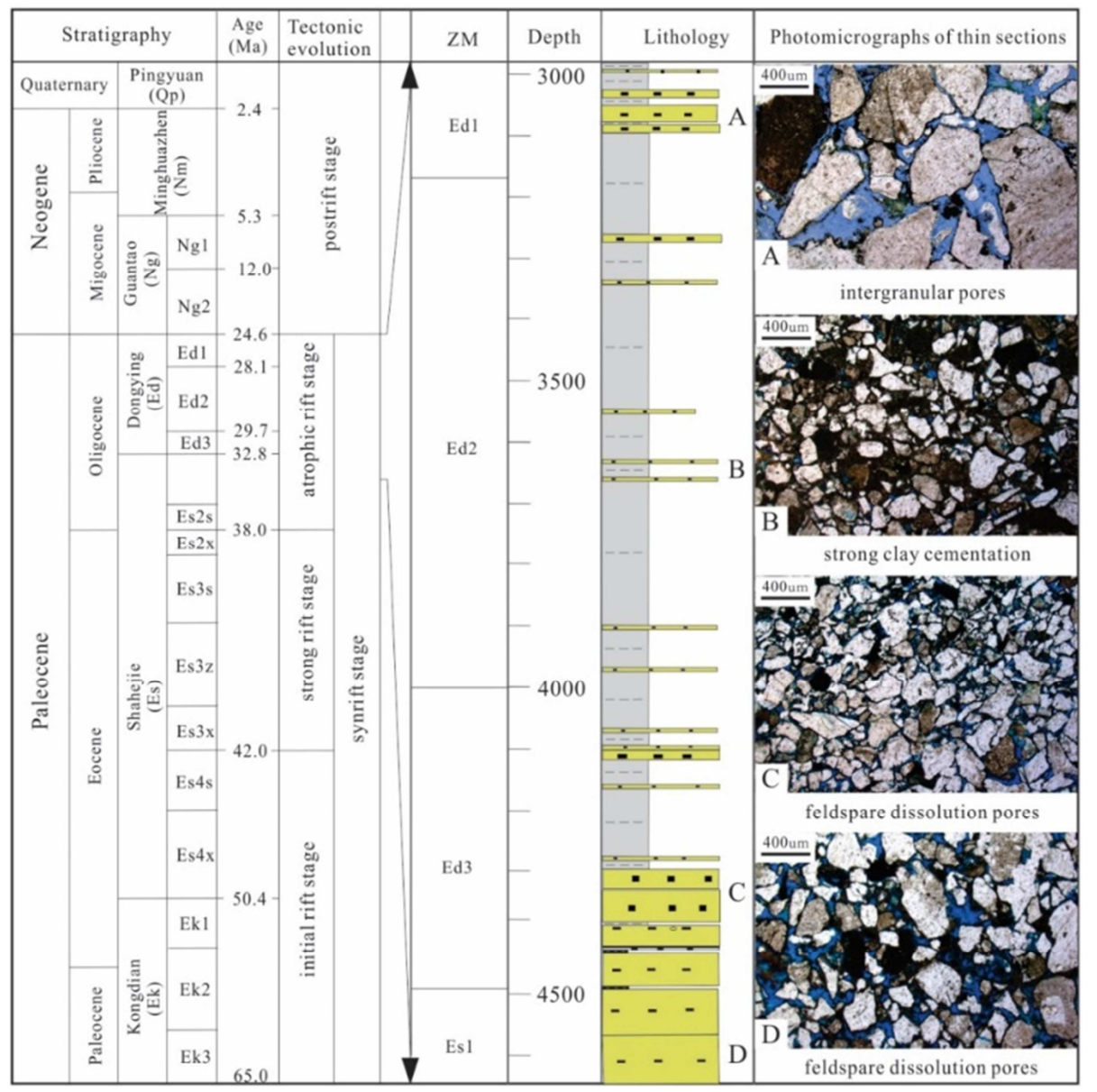

Figure 1. Tectonic setting of Bozhong depression in Bohai Basin and diagenesis in Dongying Formation and Shahejie Formaiton. 


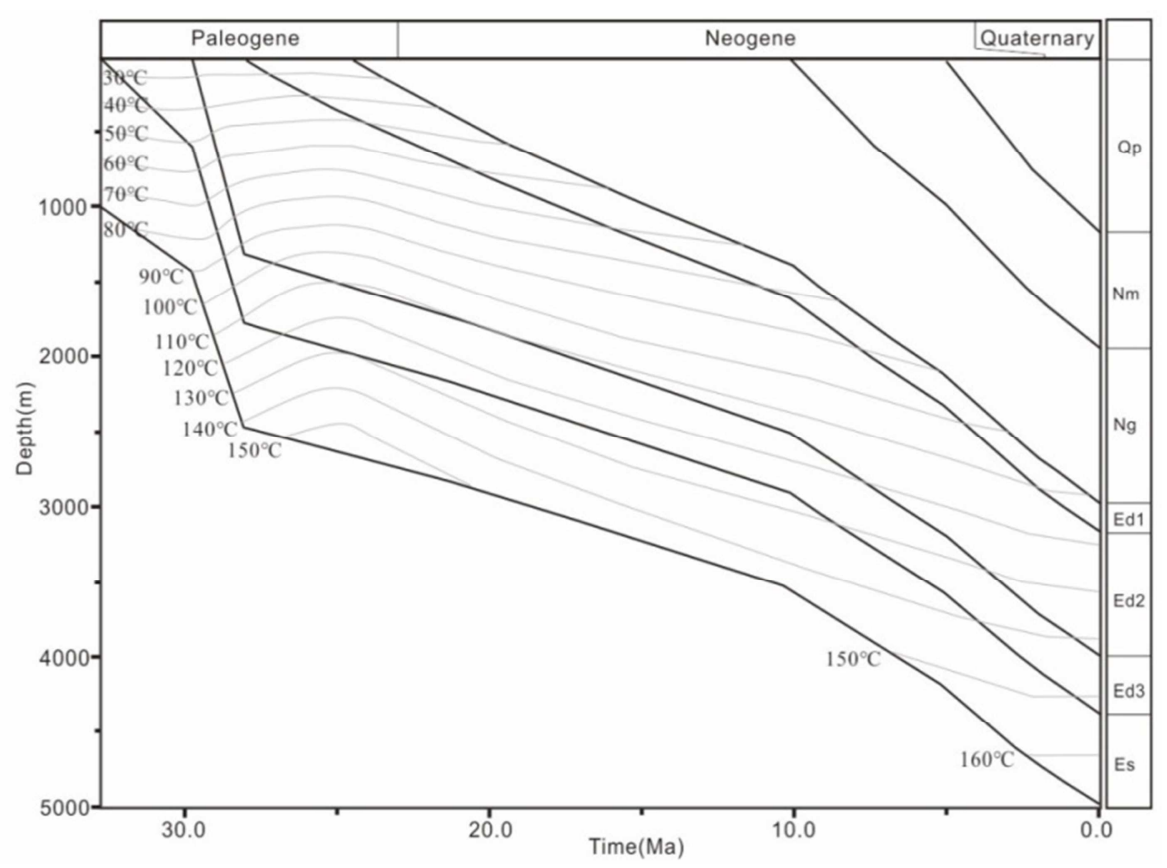

Figure 2. Burial and thermal modeling of well $X$.

\subsection{Method for Diagenetic Facies Prediction}

\subsubsection{Diagenesis Facies Division}

Diagenetic facies refers to the geological bodies formed by various diagenesis under the control of diagenesis and with certain geometric forms, specific diagenetic structures and specific diagenetic minerals. Similar to concept of sedimentary facies and logging facies, the significance of the diagenetic facies is the collection of the final state of a reservoir under the joint action of structure, fluid, temperature and pressure, which is the sum of petrological, geochemical characteristics and petrophysical characteristics under the diagenetic environment, and its essence is the mineral composition and fabric appearance. The composition and texture features of the reservoir are mainly the genetic markers of the properties, types and advantages of the reservoir, which can be used to study formation mechanism, spatial distribution and quantitative evaluation of the reservoir. Prediction of favorable porosity and permeability of diagenetic facies is the focus of reservoir research and oil and gas exploration. The division of diagenetic facies is very general when diagenetic facies is divided into constructive diagenesis, destructive diagenesis and maintaining diagenetic facies according to the effect of diagenesis on the porosity of the reservoir (Zhou Caineng, 2008). On the main diagenesis, the diagenetic facies of clastic reservoir can be divided into strongly compacted diagenetic facies, strongly dissolved diagenetic facies and strong cementaion diagenetic facies.
There are also comprehensive naming, such as weak compacted-strong cementaion facies, while the mineral types are used in the division, such as carbonate dissolution-feldspar dissolution facies. In short, these criteria are different, random and quantitative, which are not conducive to the fine study of diagenetic facies.

In our research, Rcompaction, Rcementation and Rdissoluiton are taken into consideration for diagenetic facies (DF) division in clastic rock (table 1). Formula (1) is naming methods of diagenetic facies. Prior to a quantitative description of diagenetic facies, data including Rcompaction, Rcementation, Rdissolution and Vprimary is needed (Formula 2-5).

$$
\mathrm{DF}=\mathrm{A} \_\mathrm{M}-\mathrm{j}-\mathrm{B} \_\mathrm{M}-\mathrm{j}-\mathrm{C}
$$

$$
\begin{gathered}
\text { Rcompaction }=(\text { Vcompaction/ Vprimary }) \times 100 \% \\
\text { Rcementation }=(\text { Vcementation } / \text { Vprimary }) \times 100 \% \\
\text { Rdissolution }=(\text { Vdissolution } / \text { Vprimary }) \times 100 \% \\
\text { Vprimary }=20.91+22.9 / \text { So }
\end{gathered}
$$

Where Vprimary is primary pore volume; so is sorting coefficient; Vcompaction is pore volume destroyed by compaction; Vdissolution is dissolution pore volume; Rcompaction is porosity compaction loss percentage; Rcementation is porosity cementation loss percentage; Rdissolution is porosity dissolution increase percentage.

Table 1. Division of diagenetic facies in clastic rocks.

\begin{tabular}{lllllll}
\hline Compaction Facies & & Cementation Facies (Mono Mineral M-j) & \multicolumn{2}{l}{ Dissolution Facies (Mono Mineral M-j) } & Diagenetic \\
\hline Type (A) & Rcompaction(\%) & Type(B) & Rcementation(\%) & Type(C) & Rdissolution(\%) & Facies (A+B+C) \\
\hline Strong Compaction & $>40$ & Strong Cementation & $>20$ & Strong Dissolution & $>20$ & \\
Middle Compaction & $>20 \sim 40$ & Middle Cementation & $>10 \sim 20$ & Middle Dissolution & $>10 \sim 20$ & A_M-j-B_M-j-C \\
Weak Compaction & $>0 \sim 20$ & Weak Cementation & $>0 \sim 10$ & Weak Dissolution & $>0 \sim 10$ & \\
\hline
\end{tabular}




\subsubsection{Diagenesis and Modeling}

Reservoir diagenesis modeling has been proposed by researchers to quantitatively calculate compaction percentage, dissolution percentage and cementation percentage. It mainly consists of compaction model to calculate percent of original porosity destroyed by compaction (Rahid D. Dzevanshir et al, 1985; D. Marc Audet et al., 1994; David B. Bahr et al., 2001). Cementation model to calculate percent of original porosity destroyed by cementation (Randolph T. Williams et al., 2014;). Dissolution model to calculate percent of porosity reconstructed by dissolution (Carthers W W, Kharaka Y K, 1978; Craig E. Manning, 1994; Yang Yunkun Liu Bo et al., 2013; Sun Zhixue et al., 2010). The numerical simulation methods fall into two major categories. The first category is based on physical or chemical model, which use single factor model to simulate the effect of diagenesis on pores while the other one only considers the comprehensive results of diagenesis on pores, but not caring about concrete diagenesis (Zhang Jinliang, et al., 2013; Jian Wang, Yingchang Cao, et al., 2017, Qian Wendao et al., 2017).

In this paper, the effect of different diagenesis on pores in burial history is simulated firstly with models including
Davie model (Formula 6) for compaction calculation, Olac Walderhaug model for quartz cementation calculation (Formula 7), Carthers models for feldspar dissolution calculation (Formula 10). Because both carbonate and clay cementation percentage and dissolution percentage with time or depth have not been discussed in previous studies, new methods are used to discuss their effect on pores evolution based on individual well data in study area (Figure 3, Figure 4, Formula 8, 9, 11). Then the diagenetic facies of clastic reservoir was quantificationally identified in burial history to describe reservoir diagenesis type, intensity and its evolution (Figure 2).

$$
\mathrm{V}_{\mathrm{Com}}=\partial_{1} *\left(\frac{e^{-c g\left(\rho_{\mathrm{s}}-\rho_{w}\right) z}}{e^{-c g\left(\rho_{\mathrm{s}}-\rho_{w}\right) z}+k_{1}}\right)
$$

Where $\mathrm{k}_{1}=\left(1-\Phi_{0}\right) / \Phi_{0} ; \rho_{s}=2650 \mathrm{~kg} / \mathrm{m}^{3} ; \rho_{\mathrm{w}}=1.0 \times 10^{3} \mathrm{~kg} / \mathrm{m}^{3}$; $\mathrm{c}=3.68 \times 10^{-8} \mathrm{~Pa}^{-1}, \mathrm{~g}=9.8 \mathrm{~N} / \mathrm{kg} ; \mathrm{z}$ is burial depth; $\mathrm{V}_{\mathrm{Com}}$ is the volume destroyed by compaction, and $\partial_{1}=1.2, \partial_{1}=1.0$, $\partial_{1}=0.75$ represent strong compaction, middle compaction and weak compaction respectively.

$$
\mathrm{V}_{\mathrm{Qua}_{-} \mathrm{Cem}}=\partial_{2} *\left(V q_{2}-\left(\Phi_{0}-\left(\Phi_{0}-V q_{1}\right) * \exp \frac{- \text { MaAo }}{\rho \Phi_{0} b c \ln 10}\left(10^{b T_{2}}-10^{b T_{1}}\right)\right)\right)
$$

Where $\mathrm{a}=1.98 \times 10^{-22}$ moles $/ \mathrm{cm}^{2} \mathrm{~s} ; \mathrm{b}=0.022^{\circ} \mathrm{C}^{-1} ; \mathrm{M}$ is the molar mass of quartz $(60.09 \mathrm{~g} / \mathrm{mole}) ; \rho$ is the density of quartz $\left(2.65 \mathrm{~g} / \mathrm{cm}^{3}\right) ; \mathrm{T}$ is reaction temperature $\left({ }^{\circ} \mathrm{C}\right) ; \mathrm{Vq}_{2}$ is the amount of quartz cement $\left(\mathrm{cm}^{3}\right)$ precipitated from time $T_{1}$ to $\mathrm{T}_{2} ; \mathrm{Vq}_{1}$ is the amount of quartz cement present at time $\mathrm{T}_{1} ; \mathrm{A}_{0}$ is initial quartz surface area; $\partial_{2}$ is cementation strength, and $\partial_{2}=1.2, \partial_{2}=1.0, \partial_{2}=0.75$ represent strong quartz cementation, middle quartz cementation and weak quartz cementation respectively.

$$
\begin{gathered}
\mathrm{V}_{\mathrm{Clay}_{-} \mathrm{Cem}}=\partial_{3} *\left(0.000000000001478 * \mathrm{X}^{\wedge} 4-0.00000001012 *\right. \\
\left.\mathrm{X}^{\wedge} 3+0.00001708 * \mathrm{X}^{\wedge} 2+0.001617 * \mathrm{X}+0.2806\right)
\end{gathered}
$$

Where $\mathrm{X}$ is burial depth, $\mathrm{m} ; \mathrm{V}_{\text {Clay Cem }}$ is porosity destroyed by clay cementation. $\partial_{3}$ is cementation strength, and $\partial_{3}=2$, $\partial_{3}=1.0, \partial_{3}=0.5$ represent strong clay cementation, middle clay cementation and weak clay cementation respectively.

$$
\begin{gathered}
\mathrm{V}_{\mathrm{Car} \_\mathrm{Cem}}=\partial_{4} *\left(7.39 \mathrm{e}-13 * \mathrm{X}^{\wedge} 4-5.06 \mathrm{e}-09 * \mathrm{X}^{\wedge} 3+8.54 \mathrm{e}-06 * \mathrm{X}^{\wedge} 2\right. \\
+0.0008085 * \mathrm{X}+8.005 \mathrm{e}-15)
\end{gathered}
$$

Where $\mathrm{X}$ is burial depth, $\mathrm{m}$; $\mathrm{V}_{\mathrm{Car} \_\mathrm{Cem}}$ is porosity destroyed by carbonate cementation. $\partial_{4}$ is cementation strength, and $\partial_{4}=2, \partial_{4}=1.0, \partial_{4}=0.5$ represent strong carbonate cementation, middle carbonate cementation and weak carbonate cementation respectively.

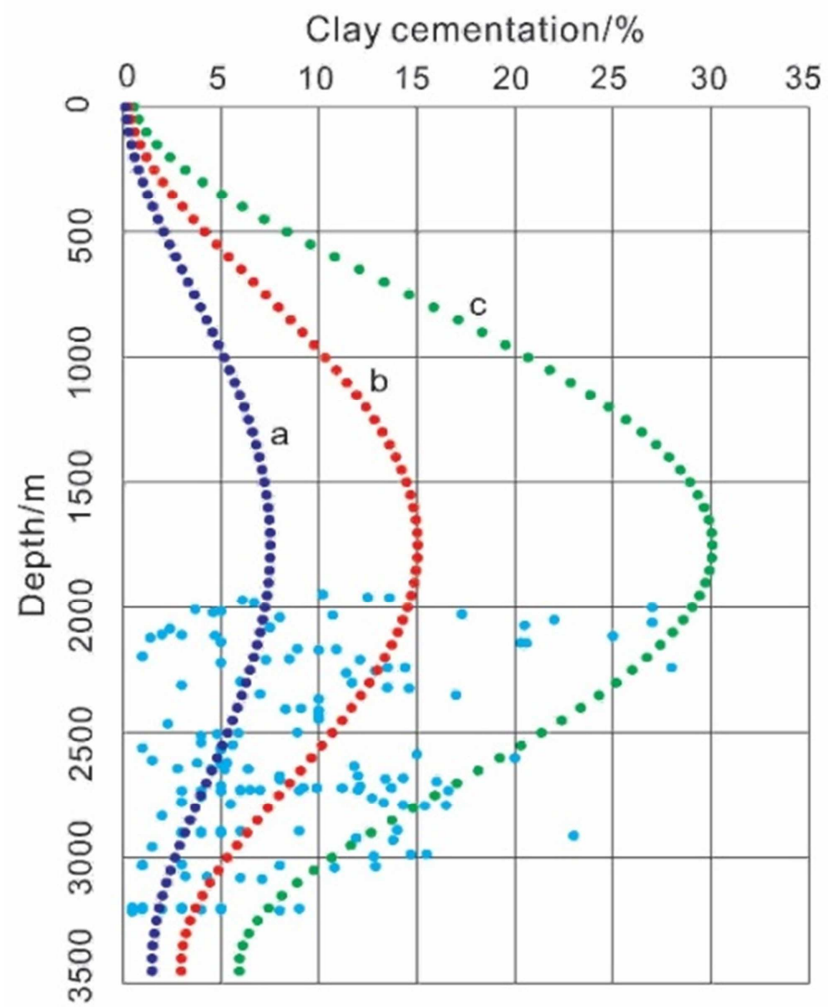

Figure 3. Percentage composition of clay mineral in the vertical direction and nonlinear curve fitting to analyzing the experiment data. Curve $c$ represents strong clay cementation; Curve $b$ represents middle clay cementation; Curve a represents weak clay cementation. 


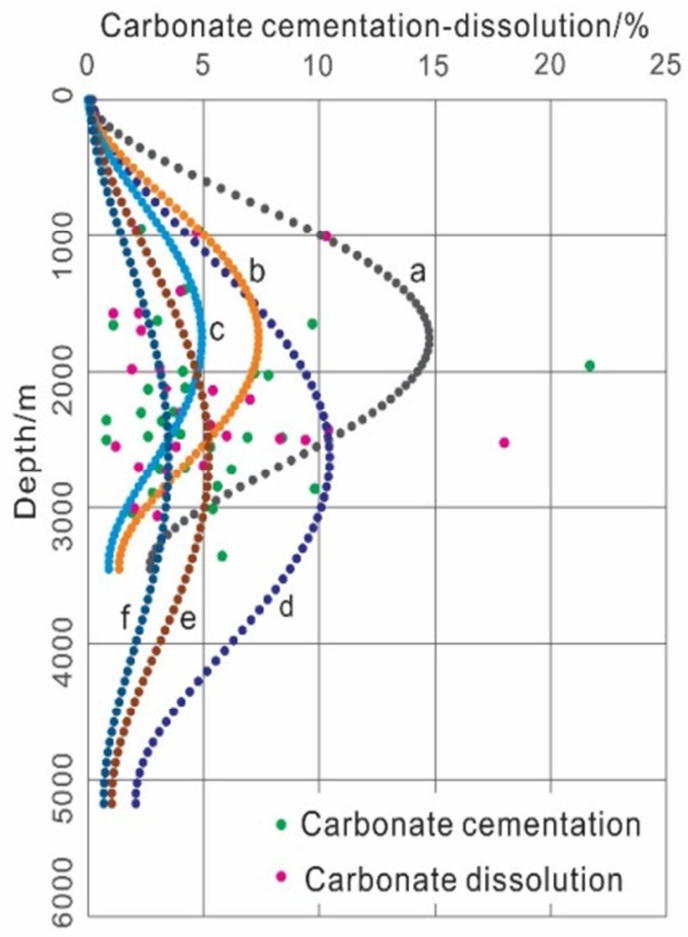

Figure 4. Percentage composition of carbonate cementation and dissolution in the vertical direction and nonlinear curve fitting to analyzing the experiment data. Curve a represents strong carbonate cementation; Curve $b$ represents middle carbonate cementation; Curve $c$ represents weak carbonate cementation; Curve d represents strong carbonate dissolution; Curve e represents middle carbonate dissolution; Curve f represents weak carbonate dissolution.

$$
\mathrm{V}_{\mathrm{Fel} \_ \text {Dis }}=\partial_{5} *\left(\frac{0.2 \Delta \Phi}{\Delta \mathrm{t}^{3}}\left(t-t_{1}\right)^{3}+\frac{0.3 \Delta \Phi}{\Delta \mathrm{t}^{2}}\left(t-t_{1}\right)^{2}\right)
$$

Where $\mathrm{t}$ is reaction time, Ma; $\Delta \emptyset$ is average porosity, $\% ; \mathrm{t}_{1}$ is temperature at $70^{\circ} \mathrm{C}$ for the first time, $\mathrm{Ma} ; \mathrm{t}_{2}$ is temperature at $90^{\circ} \mathrm{C}$ for the first time, Ma; $\Delta \mathrm{t}=\mathrm{t}_{1}-\mathrm{t}_{2} ; \mathrm{V}_{\mathrm{Fel} \text { Dis }}$ is porosity reconstructed by feldspar dissolution. $\partial_{5}$ is cementation strength, and $\partial_{5}=1.5, \partial_{5}=1.0, \partial_{5}=0.25$ represent strong feldspar dissolution, middle feldspar dissolution and weak feldspar dissolution, respectively.

$\mathrm{V}_{\text {Car_Dis }}=\partial_{6} *\left(1.014 \mathrm{e}-13 * \mathrm{X}^{\wedge} 4-1.041 \mathrm{e}-09 * \mathrm{X}^{\wedge} 3+2.636 \mathrm{e}-06 * \mathrm{X}\right.$

$$
\wedge 2+0.0003743 * X+0.09743)
$$

Where $\mathrm{X}$ is burial depth, $\mathrm{m} ; \mathrm{V}_{\mathrm{Car} \text { Dis }}$ is porosity reconstructed by carbonate dissolution. $\partial_{6}$ is dissolution strength, and $\partial_{6}=2, \partial_{6}=1.0, \partial_{6}=0.5$ represent strong carbonate dissolution, middle carbonate dissolution and weak carbonate dissolution respectively.

The pore volume destroyed by compaction (Vcompaction) and cementation (Vcementation) is calculated using equation (6), (7), (8), (9) respectively, while the porosity reconstructed by dissolution (Vdissolution) is calculated using Equation (10) and (11).

\section{Results}

\subsection{Pores Evolution}

The evolution of pores is a process of reduction and disappearance of primary pores and formation and reduction of secondary pores (Stephan Stricker et al., 2015; Guanghui Yuan et al., 2016). In the long history of geological history, the strong cementation and filling have resulted in the almost complete loss of primary pores, such as interframe pores and cavity holes, which are the main destructive diagenesis. The main constructive diagenetic events in the burial diagenetic environment are feldspar dissolution and carbonate dissolution from shallow buried to middle buried (Figure 5, Table 2). The loss of primary porosity caused by compaction and cementation is ranging from $13.2 \% \sim 21.1 \%$ and $8.7 \% \sim 13.8 \%$, respectively, while the increase of porosity caused by dissolution is ranging from $3.8 \% \sim 11.7 \%$.

\begin{tabular}{|c|c|c|c|c|c|c|c|}
\hline Formation & t (Ma) & $\operatorname{Rcom}(\%)$ & Rdis-Fel (\%) & Rdis-Car (\%) & Rcem-Clay (\%) & Rcem-Que (\%) & Rcem-Car (\%) \\
\hline \multirow{4}{*}{ Ed1 } & 24.6 & & & & 0.9 & & 1.1 \\
\hline & 12 & 17.3 & & & 7.7 & & 19.9 \\
\hline & 2.4 & 33.1 & 2.7 & 3.3 & 16.5 & 1.7 & \\
\hline & 0 & 38.0 & 3.9 & 5.8 & 19.5 & 4.2 & \\
\hline \multirow{4}{*}{ Ed2 } & 24.6 & 10.0 & & & 2.7 & & \\
\hline & 12 & 36.9 & & & 17.4 & & \\
\hline & 2.4 & 55.1 & 8.2 & & 31.8 & 4.9 & \\
\hline & 0 & 59.7 & 11.8 & & 36.1 & 7.6 & \\
\hline \multirow{4}{*}{ Ed3 } & 24.6 & 24.8 & 1.1 & & 2.8 & 0.2 & \\
\hline & 12 & 39.3 & 11.6 & & 14.6 & 3.6 & \\
\hline & 2.4 & 51.0 & 20.4 & & 21.5 & 9.3 & \\
\hline & 0 & 54.9 & 23.7 & & 23.8 & 12.1 & \\
\hline \multirow{4}{*}{ Es1 } & 24.6 & 24.1 & & & 3.7 & & 9.5 \\
\hline & 12 & 32.2 & 16.6 & 7.2 & 12.4 & & 11.3 \\
\hline & 2.4 & 38.2 & 23.8 & 12.0 & 15.9 & & \\
\hline & 0 & 42.2 & 26.9 & 14.5 & 17.4 & & \\
\hline
\end{tabular}

Table 2. Porosity compaction loss percentage, porosity cementation loss percentage and porosity dissolution increase percentage at critical time.

Note: Rcom is porosity compaction loss percentage; Rdis-Fel is porosity increase percentage by feldspar dissolution; Rdis-Car is porosity increase percentage by carbonate dissolution; Rcem-Clay is porosity loss percentage by clay cementation; Rcem-Que is porosity loss percentage by quartz cementation; RcemCar is porosity loss percentage by carbonate cementation. 

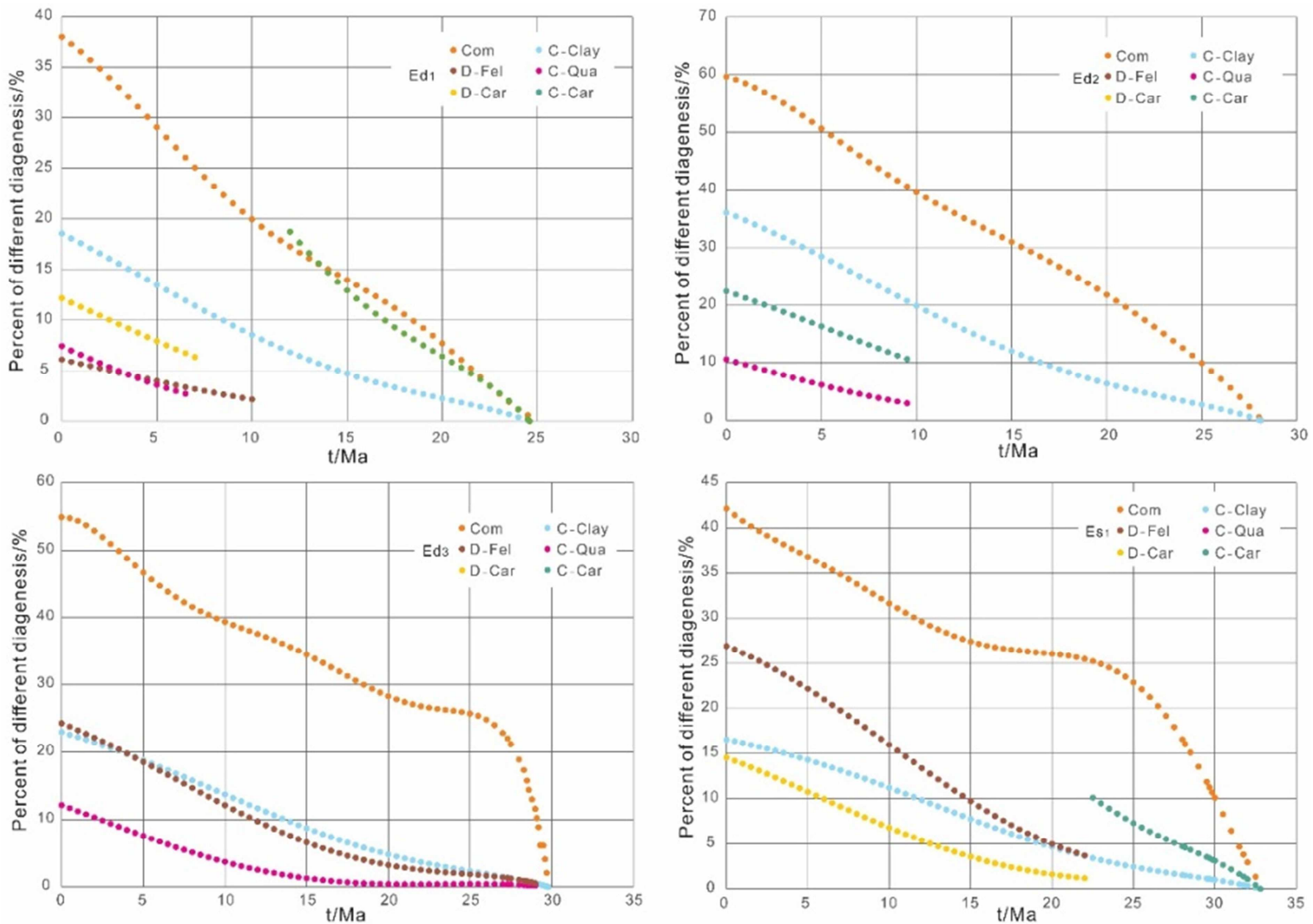

Figure 5. Different diagenesis and its effect on pores evolution in Bozhong X oilfield.

\subsection{Diagenetic Facies}

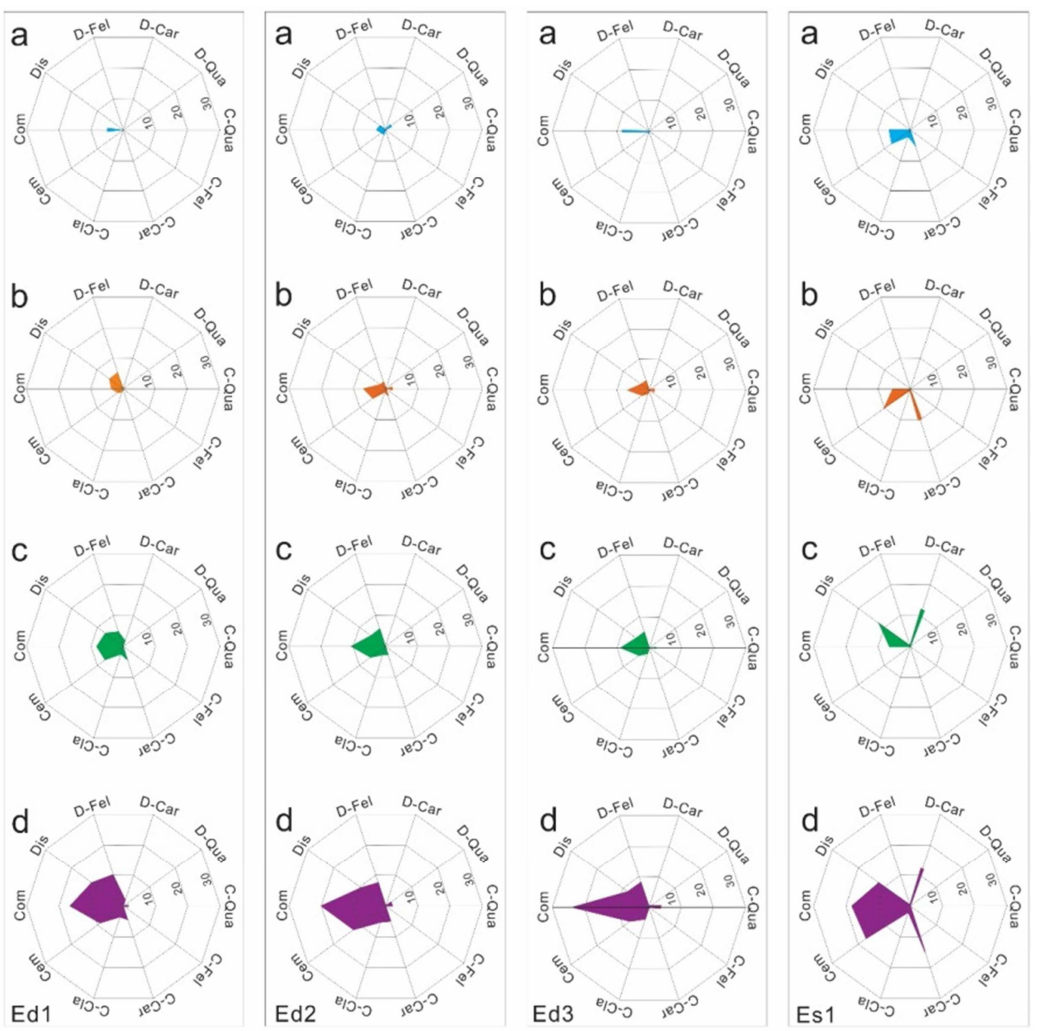

Figure 6. Diageneitc facies evolution in burial progress in Bozhong X oilfield; $a$ is the period of Guantao formation sedimentation (24.6 Ma); $b$ is the period of Minghuazhen formation sedimentation (12.0 Ma); $c$ is the period of Plain formation sedimentation (2.4 Ma); $d$ is at present. 
The evolution process of the diagenetic facies of the Paleogene lake sediment sandstone are quantitatively calculated and restored. Numerically, the $\operatorname{Ed}_{1}$ reservoir of Paleogene lake sediment sandstone in Bozhong X oilfield has experienced such an evolutionary process of W-Com_W-Cla-C_M-Car-C M-Com M-Clay-C W-Qua-C W-Fel-D W-Car-D to M-Com_M-Cla-C_W-Qua-C_W-Fel-D_W-Car-D, while the $\mathrm{Ed}_{2}$, the $\mathrm{Ed}_{3}$ and the $\mathrm{Es}_{1}$ are $\overline{\mathrm{W}}-\mathrm{Com} \mathrm{W}-\mathrm{Cla}-\mathrm{C}$ to M-Com_M-Cla-C-S-Com_S-Clay-C_W-Qua-C_W-Fel-D to S-Com_S-Cla-C_W-Qua-C_M-Fel-D,

M-Com_W-Cla-C_W-Qua-C_W-Fel-D

M-Com_M-Cla-C_W-Qua-C_W-Fel-D

S-Com_M-Clay-C_W-Qua-C_S-Fel-D

S-Com_S-Clay-C_M-Qua-C_S-Fel-D

M-Com W-Cla-C W-Car-C

M-Com M-Cla-C W-Car-C M-Fel-D W-Car-D

M-Com_M-Clay- $\bar{C}$ S-Fel-D M-Car-D to S-Com M-Cla-C S-Fel-D_ M-Car-D respectively. W, M, S representing diagenetic strength, are weak, middle and strong, while Com, $\mathrm{D}$ and $\mathrm{C}$ are diagenesis in diagenesis progress. Cla, Qua, Fel, Car represent different minerals (Figure 6).The diagenetic facies sequences reveal that the diagenetic environment of the Paleogene lake sediment sandstone formation has experienced an evolution process from weak-alkalinity, weak-acidity, acidity, acid-alkaline transition successively. It indicated that compaction which last in the entire burial process is the primary factor of decreasing reservoir porosity. The dissolution during acid environment between the early and late diagenetic stage leads to the formation of favorable reservoir of the Paleogene lake sediment sandstone in the study area.

\section{Discussion}

Clastic rock reservoir is one of the most important oil and gas reservoirs in China, and diagenesis has great influence on reservoir quality. The diagenetic facies evolution have close relation with the original composition and diagenetic field while the former is controlled by sedimentary facies and the latter is controlled by tectonism (Jian Wang et al., 2017). It is found that sedimentation is a basic factor for primitive fabric of clastic rock, and tectonism are the key factors for different diagenesis.

On the division of diagenetic facies, diagenesis facies is a product of different diagenetic environments. It mainly displays the changes in the filling materials, debris components and pore structure during diagenesis, and these changes are directly controlled by the diagenetic environment, including the formation temperature, pressure, hydrodynamic system, water medium properties and original component. The formation and production of various authigenic minerals are often associated with certain physical and chemical conditions and specific geological and historical environments in different diagenetic environments. They are important signs in association with diagenetic facies. Therefore, the evolution of diagenetic facies sequence can indicate the formation and development of the roc (Ying Fengxiang et al., 1997; Guanghui Yuan et al., 2017).

Buried depth in early diagenetic stage A is less than $1000 \mathrm{~m}$, with paleo temperature less than $65^{\circ} \mathrm{C}$, the main diagenesis types of sandstones is mechanical compaction and carbonate cementation. The main diagenesis types of sandstones in early diagenetic stage $\mathrm{B}$ is mechanical compaction, while cementation and dissolution are undeveloped. Buried depth in middle diagenetic stage $\mathrm{A} 1$ is around $2500 \mathrm{~m}$, with paleo temperature ranging at $90^{\circ} \mathrm{C}$ to $120^{\circ} \mathrm{C}$. The main diagenesis types of sandstones in middle diagenetic stage A1 are mechanical compaction and dissolution of feldspar and debirs. Meanwhile, quartz enlargement and authigenic kaolinite can be commonly found. Buried depth in middle diagenetic stage A2 is around $3500 \mathrm{~m}$. When the temperature rises to $120^{\circ} \mathrm{C} \sim 160^{\circ} \mathrm{C}$, the mainly diagenesis is calcite and dolomite cementation.

\section{Conclusion}

A new method is presented for diagenetic facies prediction of Paleogene lake sediment sandstone in Bozhong X Oilfield. The method is primarily based on the identification of diagenesis from core, which are closely correlated with porosity and permeability. The workflow of the method is as the following: Firstly, the types of diagenetic are established based on cores data. Secondly, diagenetic models are established based on previous studies. Thirdly, due to the simulaiton data in individual well, the diagenetic facies is confirmed. The method was applied to predict the reservoir diagentic of the lake sandstones in Bozhong $\mathrm{X}$ Oilfield, Bohai Bay Basin, in which four types of diagenetic facies sequences were identified.

\section{Acknowledgements}

This research work was funded by Major Projects of National Science and Technology "Large Oil and Gas Fields and CBM development" (Grant No. 2016ZX05027). Our grateful thanks are due to Shanghai Branch of CNOOC Ltd. for their help in providing geological data. Thanks are also due to anonymous reviewers for their constructive suggestions.

\section{References}

[1] Xu Jie, Ji Fengju, 2015. The structure and evolution of the Bohai Bay Basin, Seismological Press.

[2] Jian Wang, Yingchang Cao, Keyu Liu, Jie Liu and Muhammad Kashif, 2017. Identification of sedimentary-diagenetic facies and reservoir porosity and permeability prediction: An example from the Eocene beach-bar sandstone in the Dongying Depression, China Original Research Article. Marine and Petroleum Geology, 82: 69-84.

[3] Rahid D. Dzevanshir, Leonid A. Buryakocskiy et al., 1985. Simple quantitative ecaluation of porosity of argillaceous sediments at carious depths of burial. Sedimentary Geology, 46:169-175. 
[4] D. Marc Audet and J. Desomnd C. McConell, 1992. Establishing resolution limits for tectonic subsidence curves by forward basin modeling. Marine and Petroleum, 11: 400-412.

[5] David B. Bahr, Eric W.H.Hutton et al, 2001. Exponential approximations to compacted sediment porosity profiles. Computers and Geosciences 27:691-700.

[6] Craig E. Manning, 1994. The solubility of quartz in H2O in the lower crust and upper mantle. Geochimica et Cosmochimica Acta, 58(22):4831-4839.

[7] Randolph T. Williams, John R. Farver, et al., 2014. An experimental investigation of the role of microfracture surfaces in controlling quartz precipitation rate: Applications to fault zone diagenesis. Journal of Structural Geology $74: 24-30$

[8] Carthers W W, Kharaka Y K, 1978. Aliphatic acid anions in oil-field waters: Implications for origin of natural gas. AAPG Bulletin, 62(12):2441-2453.

[9] Yang Yunkun Liu Bo et al., 2013. Dissolution response mechanism of the carbonate mieral with the increase of depth and its reservoir significance. Acta Scientiarum Naturalium Universitatis Pekinensis, 49(5):859-867.

[10] Sun Zhixue, Sun Zhilei et al., 2010. Characteristics of carbonate cements in sandstone reservoirs :A case from Yanchang Formation, middle and southern Ordos Basin China. Petroleum Exploration and Development, 37(5):543-551.

[11] Guanghui Yuan, Yingchang Cao, Jon Gluyas, Zhenzhen Jia, 2017. Reactive transport modeling of coupled feldspar dissolution and secondary mineral precipitation and its implication for diagenetic interaction in sandstones. Geochimica et Cosmochimica Acta, 207:232-255.

[12] Ying Fengxiang, He Dondbo, Long Yumei, Lin Xisheng, 2003 The division of diagenetic stages in clastic rocks (SY/T 5477-2003) (in Chinese).

[13] Zahra Sadat Mashhadi, Ahmad Reza Rabbani, Mohammad Reza Kamali et al., 2015. Burial and thermal maturity modeling of the Middle Cretaceous-Early Miocene petroleum system, Iranian sector of the Persian Gulf. Petroleum Science. 2015(03): 367-390.

[14] Orhan Mahmic, Henning Dypvik, Erik Hammer, 2018. Diagenetic influence on reservoir quality evolution, examples from Triassic conglomerates/arenites in the Edvard Grieg field, Norwegian North Sea. Marine and Petroleum Geology. 93, 247-271.

[15] Taylor, T. R., Giles, M. R., Hathon, L. A., Diggs, T.N., Braunsdorf, N. R., Birbiglia, G. V., Kittridge, M. K., Macaulay, C. I., Espejo, I. S., 2010. Sandstone diagenesis and reservoir quality prediction: models, myths, and reality. AAPG (Am. Assoc. Pet. Geol.) Bull. 94(8), 1093-1132.

[16] Jian Wang, Yingchang Cao, Keyu Liu, Jie Liu and Muhammad Kashif, 2017. Identification of sedimentary-diagenetic facies and reservoir porosity and permeability prediction: An example from the Eocene beach-bar sandstone in the Dongying Depression, ChinaOriginal Research Article. Marine and Petroleum Geology, 82: 69-84.

[17] Olav Walderhaug, 1996. Kinetic modeling of quartz cementation and porosity loss in deeply buried sandstone reservoirs. AAPG Bulletin, 80(5): 731-745.

[18] Randolph T. Williams, John R. Farver, Charles M. Onasch, Daniel F. Winslow, 2015. An experimental investigation of the role of microfracture surfaces in controlling quartz precipitation rate: Applications to fault zone diagenesis. Journal of Structural Geology 74 (2015) 24-30.

[19] R.H. Lander, O Walderhaug, 1999. Predicting porosity through simulating sandstone compaction and quartz cementation. AAPG Bulletin, 83 (3): 433-449.

[20] QIAN Wendao, YIN Taiju, ZHANG Changmin, HOU Guowei, HE Miao, Xia Min and Wang Hao 2017.Forming Condition and Geology Prediction Techniques of Deep Clastic Reservoirs Acta Geologica Sinica (English Edition), 91(supp. 1):255-256.

[21] Ying Fengxiang, Zheng junmao et al., 1997. Diagenetic sequence and model of reservoirs of coal-bearing formation for prediction oil and gas distribution.Petrolem scientific and Technological paper (In Chinese) 4:19-24.

[22] Ahmed Awadalla, Omar A. Hegab, Mohammed A. Ahmed, Saad Hassan, 2018. Burial and thermal history simulation of the Abu Rudeis-Sidri oil field, Gulf of Suez-Egypt: A1D basin modeling study. Journal of African Earth Sciences, 138: 86-101.

[23] Stephan Stricker, Stuart J. Jones, Shanvas Sathar, Leon Bowen, Norman Oxtoby, 2015. Exceptional reservoir quality in HPHT reservoir settings: Examples from the Skagerrak Formation of the Heron Cluster, North Sea, UK. Marine and Petroleum Geology, 77: 198-215.

[24] K.E. Higgs, E. M. Crouch, J. I. Raine, 2016. An interdisciplinary approach to reservoir characterisation; an example from the early to middle Eocene Kaimiro Formation, Taranaki Basin, New Zealand. Marine and Petroleum Geology, 86: 111-139.

[25] Guanghui Yuan,Yingchang Cao, Yongchao Zhang, Jon Gluyas, 2016. Diagenesis and reservoir quality of sandstones with ancient "deep" incursion of meteoric freshwaterddAn example in the Nanpu Sag, Bohai Bay Basin, East China. Marine and Petroleum Geology, 82: 444-464. 